\title{
Morphological Differences In Tardigrade Spermatozoa Induce Variation In Gamete Motility
}

\section{Kenta Sugiura}

Keio University

\section{Kogiku Shiba}

University of Tsukuba

\section{Kazuo Inaba}

University of Tsukuba

Midori Matsumoto ( $\nabla$ mmatsumo@bio.keio.ac.jp )

Keio University

\section{Research Article}

Keywords: tardigrade, mating, spermatozoa, motility, fertilization, reproduction, Paramacrobiotus sp., Macrobiotus shonaicus, imaging, morphology

Posted Date: July 15th, 2021

DOl: https://doi.org/10.21203/rs.3.rs-677012/v1

License: (c) (1) This work is licensed under a Creative Commons Attribution 4.0 International License. Read Full License

Version of Record: A version of this preprint was published at BMC Zoology on January 30th, 2022. See the published version at https://doi.org/10.1186/s40850-022-00109-w. 


\section{Abstract}

\section{Background}

Fertilization is an event at the beginning of ontogeny. Successful fertilization depends on strategies for uniting female and male gametes that developed throughout evolutionary history. In tardigrades, investigations of reproduction have revealed that released spermatozoa swim in the water to reach a female, after which the gametes are stored in her body. The morphology of the spermatozoa includes a coiled nucleus and a species-specific-length acrosome. Although the mating behaviour and morphology of tardigrades have been reported, the motility of male gametes remains unknown. Here, using a highspeed camera, we recorded the spermatozoon motilities of two tardigrades, Paramacrobiotus sp. and Macrobiotus shonaicus, which have longer and shorter spermatozoa, respectively.

\section{Results}

The movement of spermatozoa was faster in Paramacrobiotus sp. than in M. shonaicus, but the beat frequencies of the tails were equal, suggesting that the long tail improved acceleration. In both species, the head part consisting of a coiled nucleus and an acrosome did not swing, in contrast to the tail. The head part of Paramacrobiotus sp. spermatozoa swung harder during turning; in contrast, the tail of $M$. shonaicus moved more widely than the head. Finally, after mating, the spermatozoa that reached the female aggregated around the cloaca while waiting to enter her body in both tested species.

\section{Conclusions}

This study provides results for the first observations and analyses of individual spermatozoon motility in tardigrades. A comparison of the spermatozoon movements of the two tardigrades suggested that the motilities of the male gametes were affected by morphological differences, where the longer spermatozoa swam faster and the shorter ones showed more stable swimming. Swimming was mainly induced by tail movement, but the long head of Paramacrobiotus sp. spermatozoa might be especially important for turning. In addition, observations of mated female cloacae suggested that the head parts of the spermatozoa were required for aggregation around the cloaca of a mated female.

\section{Background}

Fertilization is an important event in the production of the next generation in amphimictic animals. Female and male gametes meet, and then ontogeny begins. Modes of fertilization are generally divided into two types: internal and external fertilization. In the internal mode, the union of gametes occurs inside the female's body. In contrast, in the external mode, fertilization begins in the environment. In both cases, the behavioural strategies of spermatozoa for reaching eggs show diversity and are required to increase the rate of successful fertilization [1]. 
Tardigrades, often called water bears, are aquatic animals in which females lay their eggs in their moulted shell or directly into the environment [2]. In relation to the former scenario, fertilization is thought to occur externally in Isohypsibius dastychi (Pilato, Bertolani \& Binda, 1982) because male ejaculation and female oviposition are simultaneous processes [3, 4], but in Pseudobiotus megalonyx (Thulin, 1928) and Ursulinius nodosus (Marray, 1907), internal fertilization is presumed because ejaculation occurs before egg deposition, with spermatozoa entering the female's ovary $[5,6,7,8,9]$. On the other hand, in species that lay their eggs freely, internal fertilization is expected because there is a spermatheca connected to the oviduct between the cloaca and ovary $[9,10,11,12]$. However, observations of egg laying in Paramacrobiotus sp. and Macrobiotus shonaicus (Stec, Arakawa and Michalczyk, 2018) indicated that fertilization begins after eggs are laid into the environment [13, 14]. Moreover, observations of mating behaviours have revealed that the spermatozoa of the two species are first ejaculated into the environment, after which they swim to the mating female and are stored in her spermatheca; then, oviposition occurs $[13,15]$. The morphologies of the spermatozoa have been well reported not only in these two species but also in other species belonging to the same family, Macrobiotidae $[10,14,16,17$, $18,19,20]$. Reports have demonstrated that the spermatozoa have a tail, an inflated or rod-shaped midpiece, a coiled nucleus and an acrosome. Morphological analyses and comparisons have been performed, indicating that the length of the acrosome is extremely variable among genera and suggesting that the functions of the spermatozoa are affected by morphological characters. However, information on the motility of tardigrade spermatozoa is lacking.

Here, we observed the spermatozoon motilities of two tardigrades, Paramacrobiotus sp. and $M$. shonaicus, and confirmed the mating behaviours and spermatozoon morphologies of these two species $[13,14]$. According to morphometric research, the spermatozoa of Paramacrobiotus sp. and M. shonaicus had longer and shorter acrosomes, respectively; thus, we examined and compared their movement as affected by morphological variation.

\section{Results}

\section{Observation and tracking of ejaculated spermatozoa}

Ejaculated tardigrade spermatozoa in a droplet within the $0.5 \mu \mathrm{m}$ gap under cover slips were observed under an inverted-phased microscope with a stroboscopic flash and a high-speed camera [Figure 1A, B]. The recorded movies demonstrated the detailed motilities of the spermatozoa. Each spermatozoon included a head part (an acrosome and a nucleus) and a tail located in the mid-piece [Movies S1, S2, Fig. 1E]. The gametes swam by leading with the mid-piece [Movie S3].

Most of the released spermatozoa were able to reach a female during the observation period, but some could not. The trajectories of the spermatozoa that reached a female were straight and/or curved [Figure 2A, Movie S3]. The swimming speeds were $259.3 \mu \mathrm{m} / \mathrm{sec}$ and $207.6 \mu \mathrm{m} / \mathrm{sec}$ in Paramacrobiotus sp. and M. shonaicus, respectively [Figure 2B], and the spermatozoa of the former moved significantly faster $(\mathrm{n}>$ 25 , Mann-Whitney U-test, $p<0.01)$. The beat frequency of the tails during swimming was $49.5-52.5 \mathrm{~Hz}$ 
on average [Figure 2C] and did not differ significantly between species $(n>26$, Mann-Whitney U-test, $p<$ $0.1)$.

\section{Obtaining coordinates of the motilities}

The motilities of the head parts and tail parts were analysed using Bohboh software (Bohboh Soft, Tokyo, Japan) [Movie S3]. From the obtained coordinates, trajectories of the mid-piece, head and tail were visualized [Figure 3]. In addition, normalized waveforms and curvatures corresponding to the length were calculated [Figure 3, Movie S3].

To compare the amplitude between the head and the tail, the transition of the curvature correlating to the distance from the base was obtained. In the comparison, the head parts trembled less than the tail parts ([Figure 4], F-test, $p<0.01$ ). In addition, the obtained data showed differences in amplitude between the tested species. The head curvatures of the two species showed significant differences in $63.6 \%$ of the compared positions $(1-3,6-7$, and $9-10 \mu \mathrm{m}$ from the base, F-test, $p<0.01)$. In the comparison of the tails, the curvatures were different in the $12-16 \mu \mathrm{m}$ position ( $26.3 \%$ of compared positions, F-test, $p<$ 0.01).

\section{Comparison of motility curvatures}

The obtained curvatures were categorized according to the direction of swimming (in a straight line or turning), and a comparison of motility curvatures in the two swimming patterns showed intraspecies differences in movement. In Paramacrobiotus sp., 61.0\% (36 positions/59 positions in total) of the head regions were significantly curved during turning compared with swimming in a straight line; in addition, the positions were concentrated in the range 13-48 $\mu \mathrm{m}$ [Figure 5]. The tail parts were more curved in 6 of the 31 positions (19.4\%). In contrast to the results in Paramacrobiotus sp., $3 / 13$ positions $(23.1 \%)$ of the head parts and 12 out of 21 positions in total $(57.1 \%)$ of the tail parts were widely curved during turning in M. shonaicus[Figure 5].

\section{Spermatozoa around the female's cloaca}

Fifteen minutes after ejaculation, the cloacae of the mated females were observed with scanning electron microscopy (SEM). The observations revealed that numerous spermatozoa aggregated around the cloaca [Figure 6].

\section{Discussion}

In this study, we performed the first detailed observations of the motilities of tardigrade spermatozoa. The observations clearly revealed that the spermatozoa swam with the mid-piece in the front position and moved in a straight line and/or turned. Additionally, the swimming speeds in two species were measured. 
The spermatozoa of Paramacrobiotus sp. were faster than those of $M$. shonaicus. The spermatozoa of the genus Paramacrobiotus were generally longer than those of the genus Macrobiotus; moreover, the extraordinary head length of spermatozoa in the genus Paramacrobiotus was considered to enhance spermatozoon movements [19]. Our results support this hypothesis.

The curvature values of the tails were significantly larger than those of the heads in both species. The results indicated that the movements were mainly induced by the tails. In other aquatic animals, for example, ascidians and sea urchins, although the head parts are not as large as those in tardigrades, the swimming of the spermatozoa is induced by tail movement [21]. The tails, called flagella, are formed by axonemes, and the configuration is widely conserved [22]. Axonemes have been observed in the spermatozoa of some tardigrade species; in addition, the constructions were similar to those in other animals $[10,19,23,24,25,26,27]$. Unfortunately, ultrastructural information for the tested species Paramacrobiotus sp. and $M$. shonaicus is lacking, but the formation of the axoneme is also thought to be conserved in the species, suggesting that tail motility is induced by the same mechanism. In addition, the motilities of each part were significantly greater in Paramacrobiotus sp. than in $M$. shonaicus, suggesting that the longer heads and tails of Paramacrobiotus sp. spermatozoa enhanced their movement [14]. It has been confirmed that the morphology and motility of spermatozoa work in cooperation during swimming [28]. For example, the tip of Muridae sperm, which resembles a hook, facilitates swimming, according to the increased swimming speed of the sperm [28]. Although spermatozoon cooperation in tardigrades has never been examined, the long or short head part might have an effect different from that in other spermatozoa; this could be demonstrated by a fluid physics approach as performed on human sperm [29].

In a comparison of the trajectories of the spermatozoa, the tails of the turning spermatozoa in $M$. shonaicus curved more dramatically than when the spermatozoa were swimming in a straight line, indicating that the determination of direction depended on the tail's movements. On the other hand, the extraordinarily long head parts of Paramacrobiotus sp. spermatozoa showed increased curvature during turning, suggesting that the direction, i.e., whether turning or swimming in a straight line, was affected by longer parts than the tail. Moreover, the middle of the head is the junction of the acrosome and the coiled nucleus; thus, a difference in hardness might affect movement. According to our results, the acrosome is more flexible than the coiled nucleus because the tip part of Paramacrobiotus sp. spermatozoa swung widely. In contrast, the flexible component of $M$. shonaicus spermatozoa is short; therefore, the head parts did not curve as much as those in Paramacrobiotus sp., allowing more stable swimming.

Most spermatozoa reached the female's cloaca in a few seconds. However, the spermatozoa remained aggregated around the cloaca for 15 min after swimming, suggesting that they waited to enter the spermatheca of the female. In terms of swimming, a shorter head part may provide an advantage because of its improved stability; however, a longer and more flexible construction may facilitate aggregation around the female's cloaca. In any case, more detailed investigations of reproduction in tardigrades are expected. 
The correlation of spermatozoon and egg morphologies in eutardigrades is supported by measurements of taxonomic characters [26]; for example, eggs of species that have longer acrosomes are generally conical. On the other hand, eggs of species with shorter acrosomes are usually ornamented and often have an inverted-goblet shape, suggesting that gamete morphologies could be used in species differentiation. Generally, the shapes of gametes should have some functional significance for efficient and certain reproduction. A previous study hinted at the existence of gamete morphological interference at the phase of fertilization in some species [14]. In addition, the flexible and extraordinarily long acrosome has the potential to facilitate aggregation on the egg surface. Although this study focused only on male gametes, the comparisons of motility in relation to length might provide insight into the morphological differentiation that affects one of the functions of spermatozoa. To reveal the factors affecting and benefits of morphological variation in tardigrade spermatozoa, we believe it is important to accumulate observations and knowledge in many species. As a related species, the reproductive process of Mesobiotus sp., including its mating behavior and the morphology of its gametes, has been confirmed [30]. In future investigations, if similar knowledge is accumulated for various species as is done in this study, evolutionary history can be inferred based on species differentiation in gamete features.

\section{Conclusions}

In summary, we performed detailed observations of swimming spermatozoa of tardigrades, revealing that the tail mainly induced the movement of the spermatozoa. A comparison of movements between spermatozoa with longer versus shorter acrosomes demonstrated differences in swimming speeds, waveforms and curvatures, indicating that the morphological differences of the spermatozoa in tardigrades influence their movements. The waveform differences between swimming directions suggested that the long head of Paramacrobiotus sp. spermatozoa affects turning. In addition, SEM observations of mated female cloacae suggested that the head parts are required for aggregation around the cloaca of a mated female.

\section{Methods}

\section{Tardigrade culture conditions and specimen preparation}

Two tardigrades, namely, Paramacrobiotus sp. TYO strain and M. shonaicus, were used for this investigation. These tardigrades were provided by Dr. Takekazu Kunieda and Dr. Kazuharu Arakawa, respectively. The culture conditions were the same as those described in Sugiura et al. [13]. The tardigrades were placed in plastic dishes containing $1.2 \%$ agar gel (Nacalai Tesque, Kyoto, Japan) topped with mineral water (Volvic) and then kept in the dark at $20^{\circ} \mathrm{C}$. The rotifer Lecane inermis and the green alga Chlorella vulgaris (Recenttec KK, Tokyo, Japan) were added to the culture as food sources. The water was changed every 3-5 days, and the dishes were renewed every 2-3 weeks.

Sample preparations for mating observations also followed Sugiura et al. [13]. Females in stage 3-4 that showed tightly packed ovaries were isolated in a separate culture for at least one week, and males with 
testes were separated into a different culture to prevent unexpected mating. Observations until this step were performed under a stereomicroscope (SZX10, Olympus, Tokyo, Japan).

\section{Recording motilities of the spermatozoa}

A pair of tardigrades, a female and a male, was selected to observe mating. The specimens were suspended in a droplet of water placed within a $0.5 \mu \mathrm{m}$ gap created by a U-shaped silicon sheet (AS ONE, Osaka, Japan) between two cover slips. The behaviors of the tardigrades were observed under an inverted-phased microscope (IX71, Olympus, Tokyo, Japan) with a 20x objective lens. The field was illuminated with a laboratory-made red stroboscopic LED lamp (620-630 nm, Power LED, Edison, Taiwan). The swimming motility of the released spermatozoa was video recorded using a high-speed chargecoupled device (CCD) camera (HAS-U2, DITECT, Tokyo, Japan) at 150 frames per second (fps) [31].

\section{Analyses of spermatozoon motility}

The locus of the spermatozoon was obtained by tracking the mid-piece as an indicator in ImageJ software [32], and the speed of movement (velocity curvilinear: VCL [31]) was calculated from the moving distance and the frames of the video on R software [33]. Computer-assisted sperm analysis (CASA) was mainly performed with Bohboh software (Bohboh Soft, Tokyo, Japan) [31]. The spermatozoa were divided to a head part (including a nucleus and an acrosome) and a tail part, and the coordinates of the two regions were obtained from the base (junction with the mid-piece) to tip of each part in each one micrometre position over 10 sequential frames. Normalized waveforms and curvatures were determined with the software and visualized with Image J or R [32,33]. The beat frequency was calculated by counting the wave peaks in the $5 \mu \mathrm{m}$ position of the tails and dividing the count by the elapsed time. Motility was categorized as swimming in a straight line or turning. Distinction of the nucleus and acrosome was performed according to morphometrical data available in Sugiura and Matsumoto [14] because of limited resolution. Specifically, the nucleus was defined as 0-21 $\mu \mathrm{m}$ and 0-11 $\mu \mathrm{m}$ in Paramacrobiotus sp. and $M$. shonaicus, respectively, and the acrosome was defined as the remaining region.

\section{Statistical comparisons}

Statistical comparisons were performed with a Mann-Whitney U-test or an F-test in R [33], using the "wilcox.exact" and "var.test" functions, respectively.

\section{SEM observations}

SEM observations were performed as described in Sugiura and Matsumoto [14]. Fifteen minutes after mating, eight females of each species were dehydrated in 100\% ethanol for $3 \mathrm{~h}$ and then soaked in tertialbutyl alcohol overnight. After being lyophilized with a JFD-320 device (JEOL, Tokyo, Japan), the samples were transferred onto aluminium stubs. The samples were then sputter-coated with gold and observed with a JSM 6510 (JEOL) scanning electron microscope. 


\section{Abbreviations}

CASA: computer-assisted sperm analysis

CCD: charge-coupled device

fps: frames per second

SEM: scanning electron microscopy

VCL: velocity curvilinear

\section{Declarations}

\section{Ethics approval and consent to participate}

No need.

\section{Consent for publication}

No need.

\section{Availability of data and materials}

The datasets used and/or analyzed during the current study are available from the corresponding author.

\section{Competing interests}

No.

\section{Funding}

This study was supported in part by KAKENHI Grant-in-Aids from the Japan Society for the Promotion of Science (JSPS) and Grant-in-Aid for Scientific Research in Innovative Areas -Platforms for Advanced Technologies and Research Resource "Advanced Bioimaging Support" for JSPS Fellow PD (JP18J21345 and 20D-19C-010-L08 to KeS), and a grant for Research Project from Research and Education Center for Natural Science (Keio University) to MM and KeS.

\section{Author contribution}

KeS performed all experiments and wrote the manuscript. KoS improved the methods of experiments. All authors designed the study and improved the manuscript.

Acknowledgements 
We thank to Dr. Takekazu Kunieda (University of Tokyo), Dr. Kazuharu Arakawa (Keio University) and Naoko Ishii (Keio University) for providing us the tardigrades we used. We also thank to Dr. Atsushi C. Suzuki (Keio University) for supporting the SEM experiments. We would like to thank to Dr. Ryuji Yanase, Dr. Kei Jokura, Dr. Yu Sato, Dr. Misa Shibata, Dr. Nana Terauchi, Sayaka Yamaguchi (University of Tsukuba) and Osamu Horiguchi (Okinawa Institute of Science and Technology) for supporting our study.

\section{References}

[1] Breed MD \& Moore J. Mating Systems. In Breed MD, Moore J, editors. Animal Behavior (Second Edition). Academic Press. 2015. p. 357-93.

[2] Altiero T, Suzuki AC, Rebecchi L. Reproduction, development and life cycle. In: Schill RO, editor. Water Bears: The Biology of Tardigrades, Zoological Monographs 2. Springer Nature, Basel, Switzerland; 2018. p. 211-47.

[3] Bingemer J, Hohberg K, Schill RO. First detailed observations on tardigrade mating behaviour and some aspects of the life history of Isohypsibius dastychi Pilato, Bertolani and Binda 1982 (Tardigrada, Isohypsibiidae). Zool J Linn Soc-lond. 2016;178(4):856-62.

[4] Bartel S, Hohberg K. Experimental investigations on the partner-finding behaviour of Isohypsibius dastychi (Isohypsibiidae: Tardigrada). Zool J Linn Soc-lond. 2020;188(3):878-86.

[5] von Erlanger R. Zur Morphologie und Embryologie eines Tardigraden (Macrobiotus macronyx Duj.). Vorläufige Mitteilung II. Biologisches Zentralblatt, 1895;15:772-7.

[6] Henneke J. Beiträge zur Kenntnis der Biologie und Anatomie der Tardigraden (Macrobiotus macronyx Duj.). Zeitschrift für wissenschaftliche Zoologie. 1991;97:721-51, Taf. 33.

[7] von Wenck. Entwicklungsgeschichtliche Untersuchungen an Tardigraden (Macrobiotus lacustris Duj.). Zoologische Jahrbücher. Abteilung für Anatomie und Ontogenie der Tiere. 1914;37:465-514, Taf. 35-8.

[8] Marcus E. Tardigrada. In: Bronn HG, editor. Klassen und Ordnungen des Tierreichs, Vol. 5. Leipzig: Akademische Verlagsgesellschaft. 1929;1-608.

[9] Rebecchi L, Guidi A, Bertolani R. Tardigrada. In: Jamieson BGM, editor. Reproductive Biology of Invertebrates. Progress in Male Gamete Ultrastructure and Phylogeny. Vol. IX, Part B. Oxford and IBH Publishing Co, Oxford, UK. 2000. p. 267-91.

[10] Rebecchi L. Ultrastructural study of spermatogenesis and the testicular and spermathecal spermatozoon of the gonochoristic tardigrade Xerobiotus pseudohufelandi (Eutardigrada, Macrobiotidae). J Morphol. 1997;234(1):11-24.

[11] Bertolani R. Evolution of the Reproductive Mechanisms in Tardigrades -A Review. Zool Anz. 2001;240:247-52. 
[12] Bertolani R, Rebecchi L. Tardigrada. In: Konobil E, Neill JD, editors. Encyclopedia of Reproduction vol. 4. Academic Press. 1999. p. 703-17.

[13] Sugiura K, Minato H, Suzuki AC, Kunieda T, Arakawa K, Matsumoto M. Comparison of Sexual Reproductive Behaviors in Two Species of Macrobiotidae (Tardigrada: Eutardigrada). Zool Sci. 2019;36(2):120-7.

[14] Sugiura K, Matsumoto M. Spermatozoa morphology changes during reproduction and first observation of acrosomal contact in two dioecious species of Macrobiotidae (Tardigrada: Eutardigrada). Zygote. 2021;29(1):42-8.

[15] Sugiura K, Arakawa K, Matsumoto M. Distribution of Macrobiotus shonaicus Stec, Arakawa and Michalczyk, 2018 (Tardigrada: Eutardigrada: Macrobiotidae) in Japan. Zootaxa. 2020;4767(1):56-70.

[16] Rebecchi L, Guidi A. First SEM studies on tardigrade spermatozoa. Invertebr Reprod Dev. 1991;19(2):151-6.

[17] Guidi A, Rebecchi L. Spermatozoan morphology as a character for tardigrade systematics: comparison with sclerified parts of animals and eggs in eutardigrades. Zool J Linn Soc-lond. 1996;116(12):101-13.

[18] Rebecchi L. The Spermatozoon in Tardigrades: Evolution and Relationships with the Environment. Zool Anz. 2001;240:525-33.

[19] Rebecchi L, Altiero L, Guidi A. The ultrastructure of the tardigrade spermatozoon: a comparison between Paramacrobiotus and Macrobiotus species (Eutardigrada). Invertebr Zool. 2011;8(1):63-7.

[20] Bertolani R, GuidettiR, Marchiro T, Altiero T, Rebecchi L, Cesari M. Phylogeny of Eutardigrada: New molecular data and their morphological support lead to the identification of new evolutionary lineage. Mol Phylogenet Evol. 2014;76:110-26.

[21] Ramírez-Gómez HV, Tuval I, Guerrero A, Darszon A. Analysis of sperm chemotaxis. In: Hamdoun A, Foltz KR, editors. Echinoderms, Part B. Methods in Cell Biology, Volume 151. Academic Press. 2019. p. 473-86.

[22] Nielsen MG, Turner FR, Hutchens JA, Raff EC. Axoneme-specific beta-tubulin specialization: a conserved C-terminal motif specifies the central pair. Curr Biol. 2001;11(7):529-33.

[23] Kristensen RM. On the fine structure of Batillipes noerrevangi Kristensen, 1978 (Heterotardigrada). 3. Spermatogenesis. Zeszyty Naukowa Uniwersytetu Jagiellonskiego Prace Zoologiczne. 1979;25:97-105.

[24] Rebecchi L, Guidi A. Spermatozoon Ultrastructure n Two Species of Amphibolus (Eutardigrada: Eohypsibiidae). Acta Zool. 1995;76(2):171-6. 
[25] Rebecchi L, Guidi A, Bertolani R. The spermatozoon of the Echiniscidae (Tardigrada, Heterotardigrada) and its phylogenetic significance. Zoomorphology. 2003;122:3-9.

[26] Nelson DR, Guidetti R, Rebecchi L. Tardigrada. In: Thorp JH, Covich AP, editors. Ecology and Classification of North American Freshwater Invertebrates. Academic Press. 2010. p. 455-84.

[27] Suzuki AC, Kristensen RM. Spermatozoa in the reproductive system of a hermaphroditic marine tardigrade, Orzeliscus belopus (Tardigrada: Arthrotardigrada). Zool Anz. 2014;253(6):497-511.

[28] Immler S, Moore HDM, Breed WG, Birkhead TR. By Hook or by Crook? Morphology, Competition and Cooperation in Rodent Sperm. PLoS ONE. 2007;1:e170.

[29] Taketoshi N, Omori T, Ishikawa T. Elasto-hydrodynamic interaction of two swimming spermatozoa. Phys Fluids. 2020;32:101901.

[30] Sugiura K, Matsumoto M. Reproduction of Mesobiotus: Comparison of Morphology and Behavior in the Family Macrobiotidae (Tardigrada: Eutardigrada). Zool Sci. in press.

[31] Inaba K, Shiba K. Microscopic analysis of sperm movement: links to mechanisms and protein components. Microscopy. 2018;67(3):144-55.

[32] ImageJ. https://imagej.nih.gov/ij/download.html Accessed October 30th, 2019.

[33] R core team. R: A language and environment for statistical computing. R Foundation for Statistical Computing, Vienna, Austria. Available at https://www.R-project.org Accessed Apr 5, 2016.

\section{Figures}



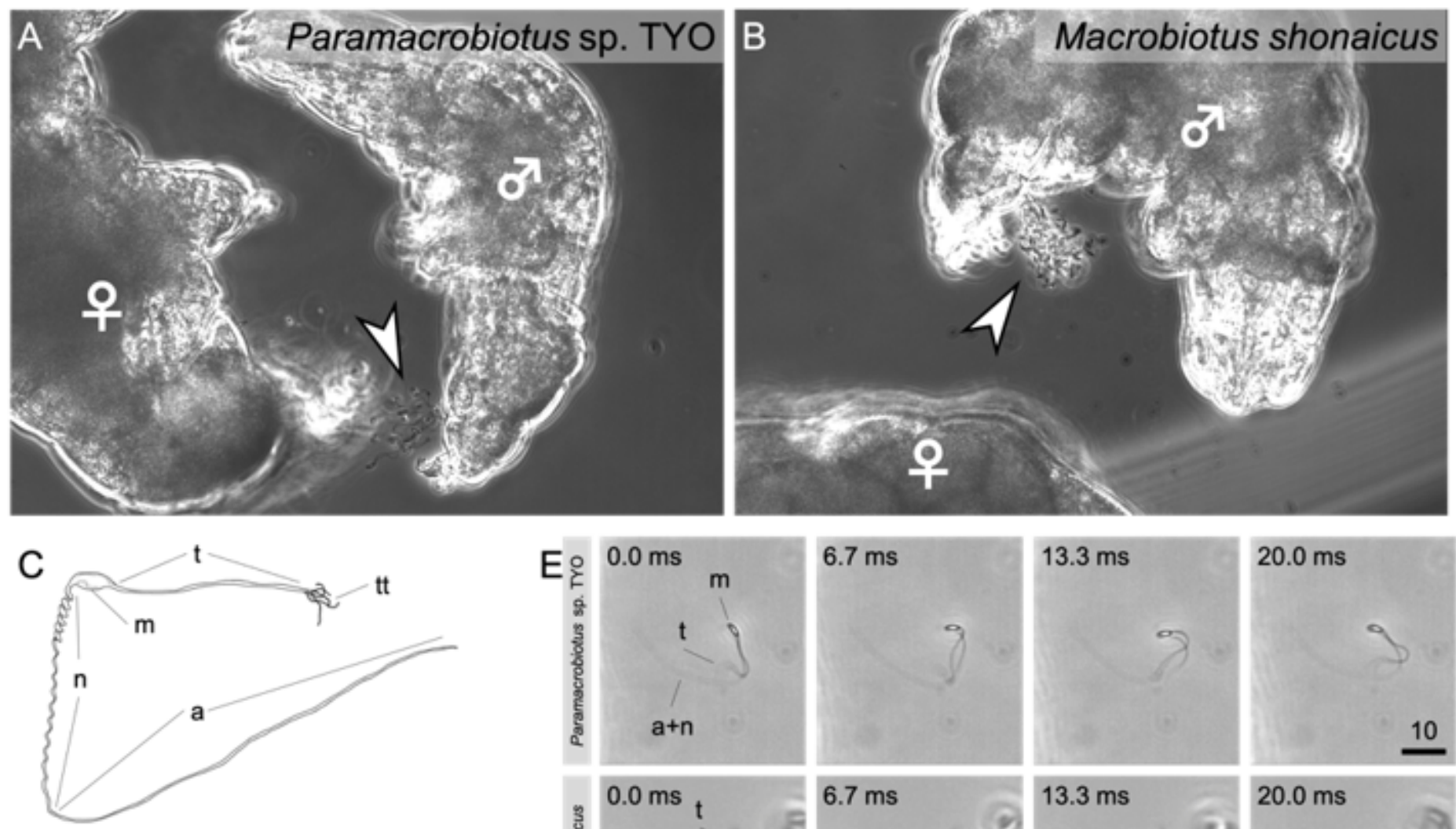

$20.0 \mathrm{~ms}$

D
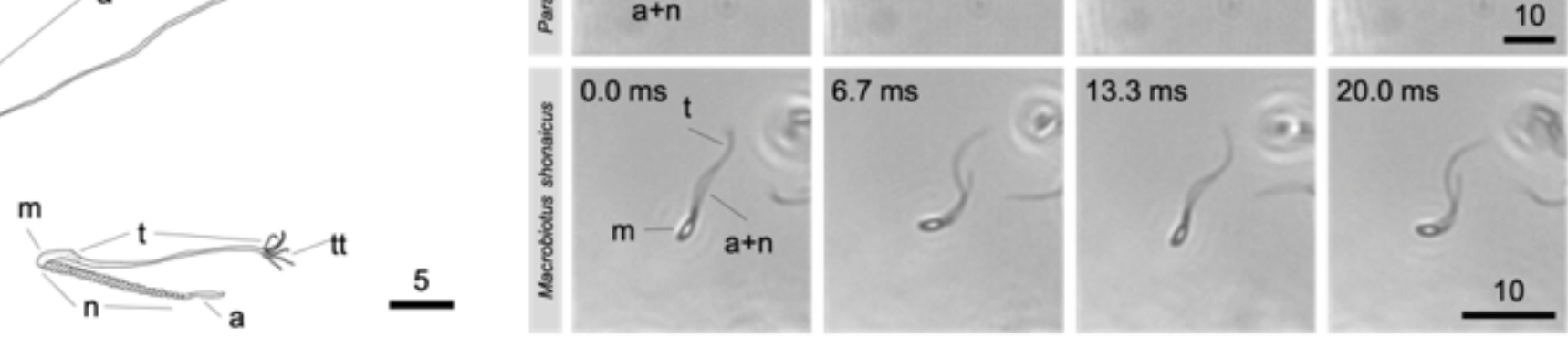

Figure 1

Observations of the ejaculated spermatozoa. A: The ejaculated spermatozoa were recorded. Arrow heads indicate the released spermatozoa. C, D: Schemas of spermatozoa of Paramacrobiotus sp. and M. shonaicus, respectively. E: Time lapse images of spermatozoa swimming. Scale bars: $\mu \mathrm{m}$. 

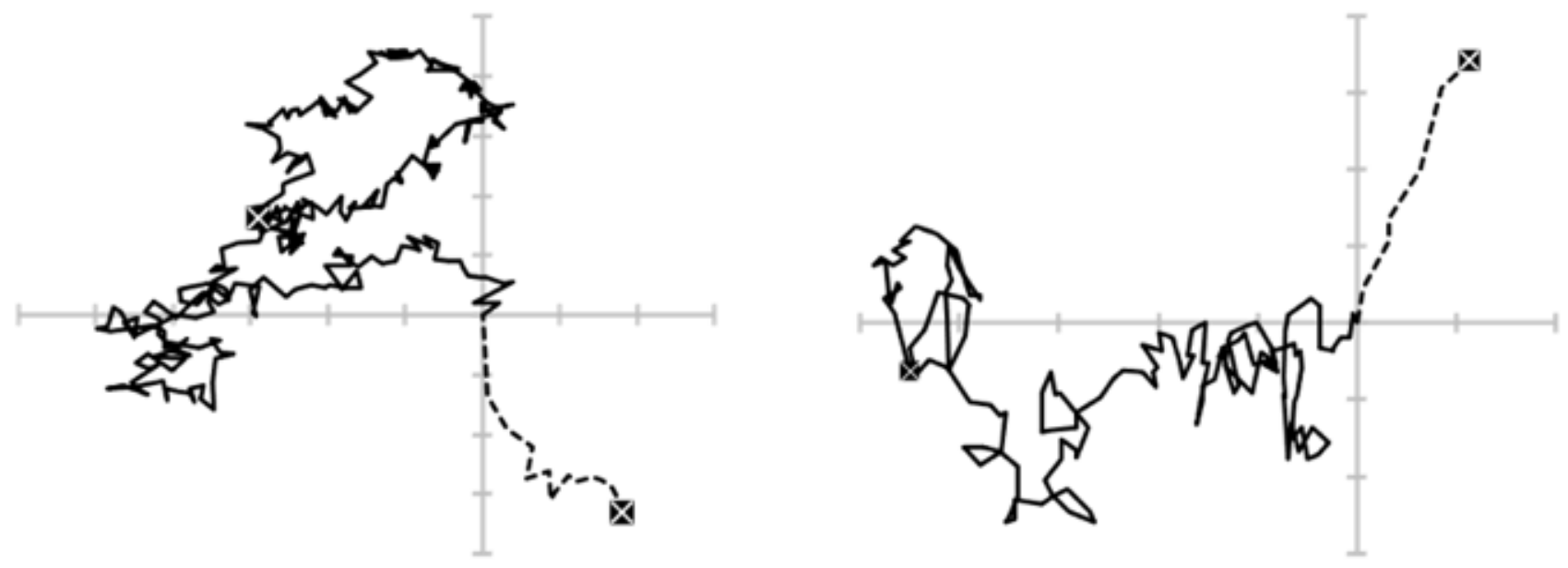

B
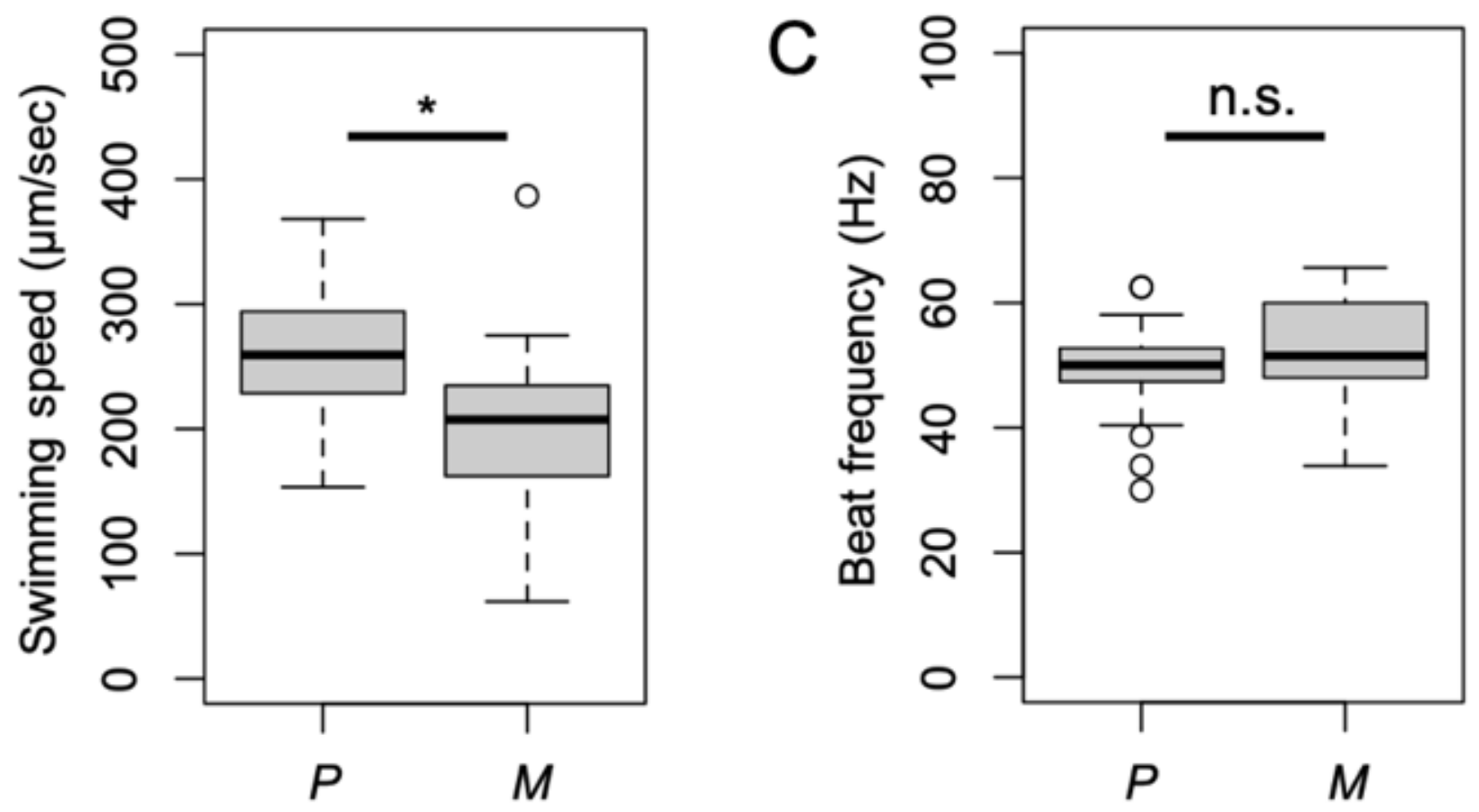

Figure 2

Tracks, speeds and beats of the spermatozoa. A: The longest (black lines) and shortest (dotted lines) swimming tracks of the respective species. " $x$ " indicates the start position. B: The swimming speeds of the spermatozoa. C: The beat frequency of tails. ${ }^{*}: p<0.01$ in the Mann-Whitney U-test, n.s.: no significant difference. 

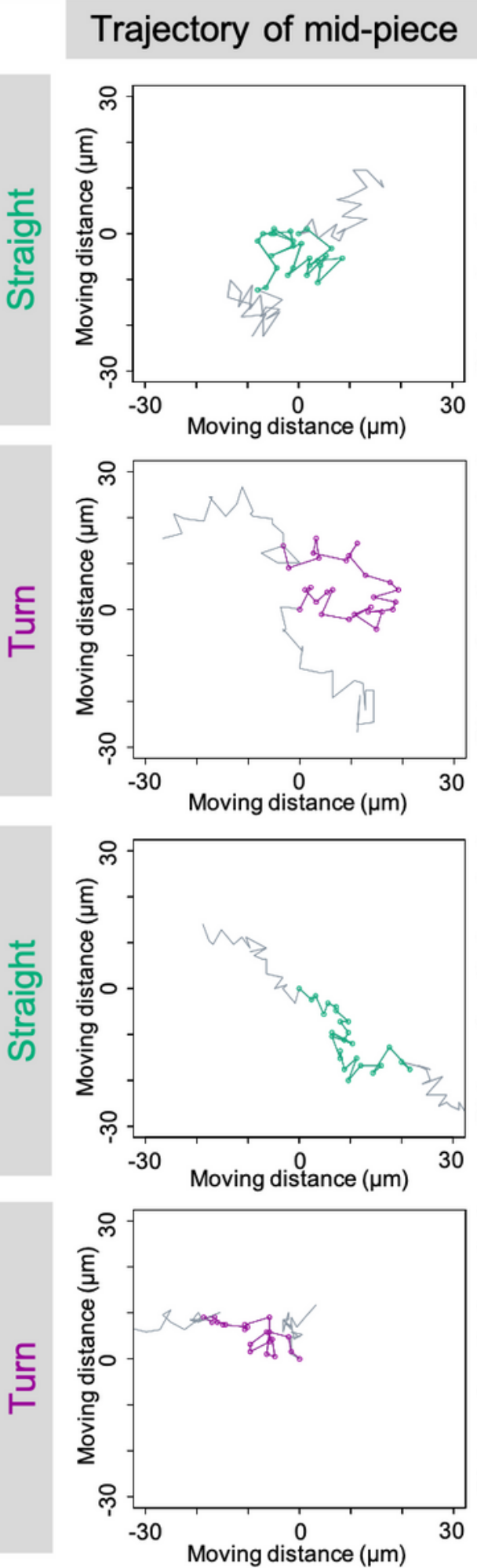

Waveform
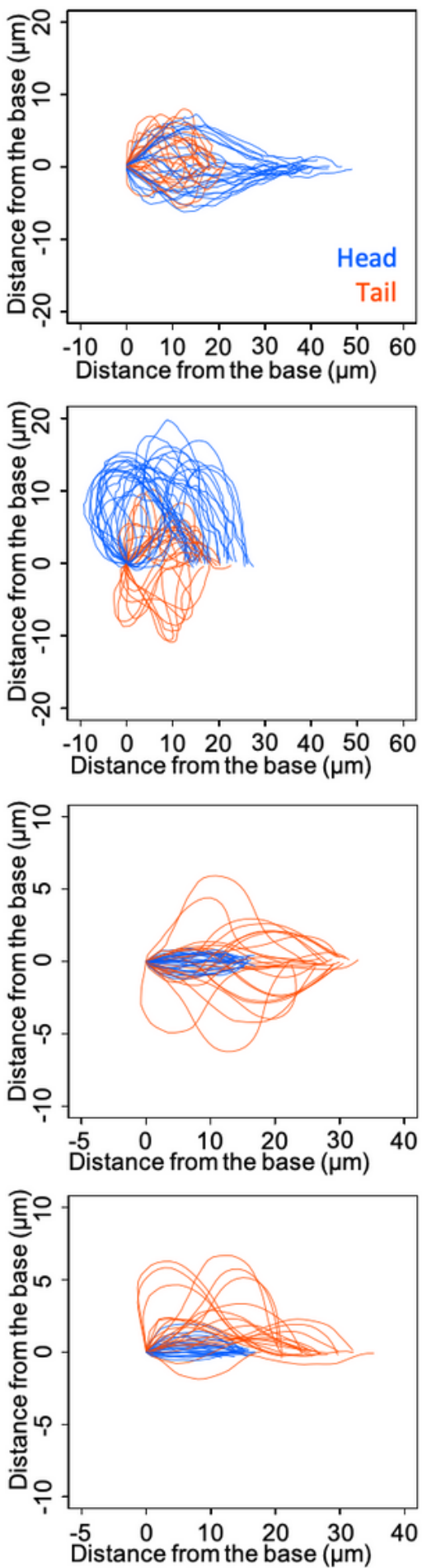

Curvature
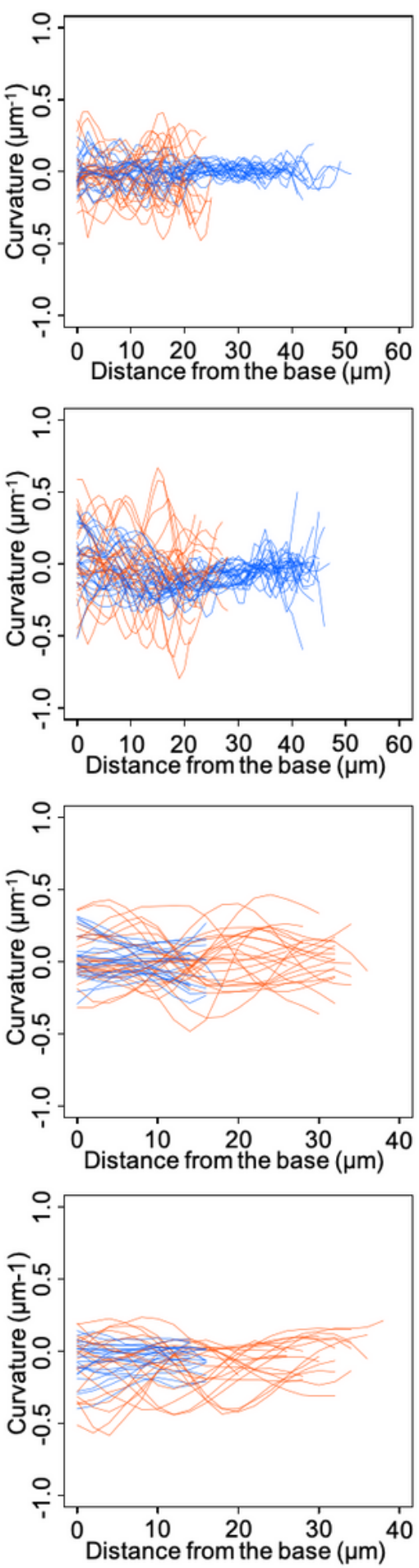

\section{Figure 3}

Spermatozoa trajectories. Obtained trajectories, normalized waveforms and curvatures of the heads and tails in the respective species. "Straight" and "Turn" indicate a spermatozoon swimming in a straight line and turning, respectively. Coloured lines of obtained trajectories correlate to waveforms in right panels. 


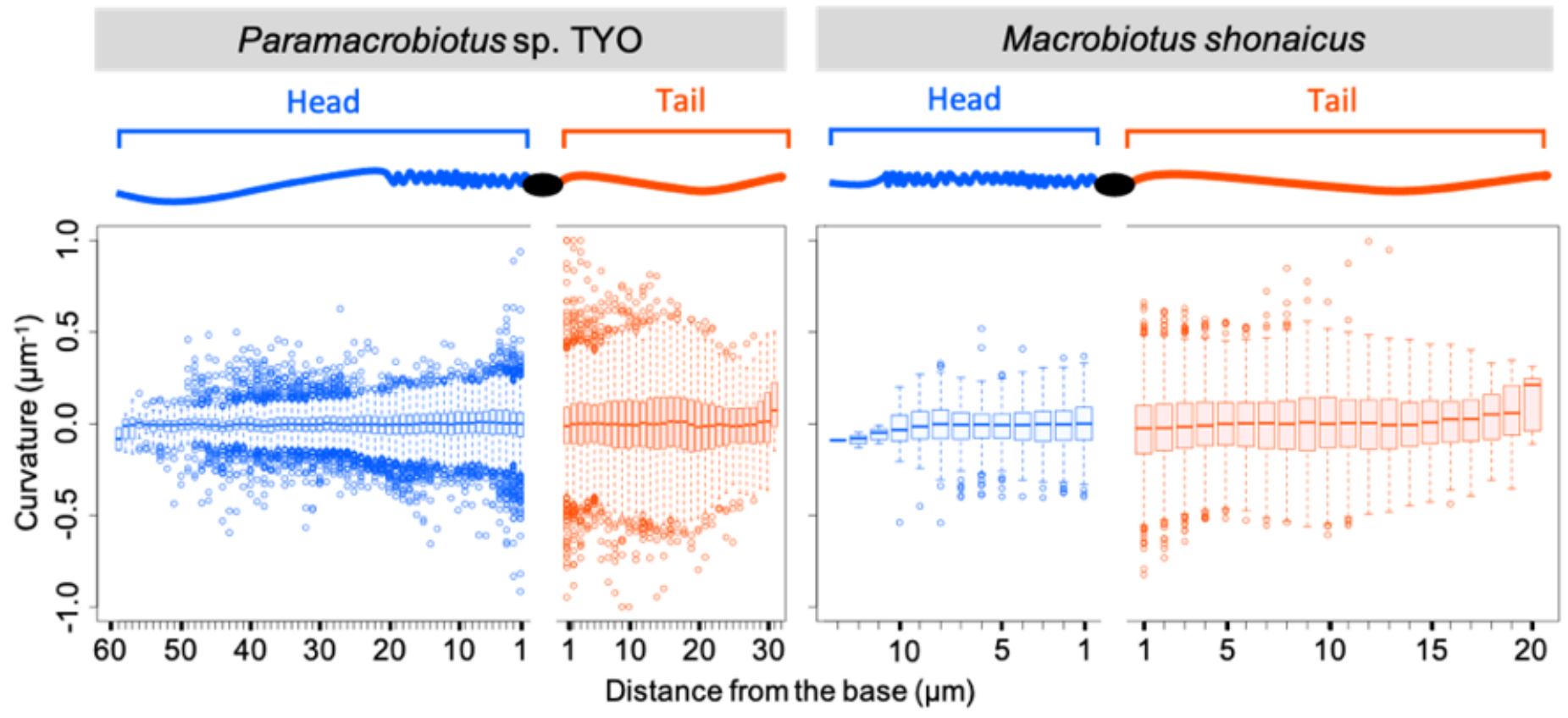

Figure 4

Spermatozoon motility comparison between parts and species. The curvatures of spermatozoa of Paramacrobiotus sp. (left) and M. shonaicus (right). 


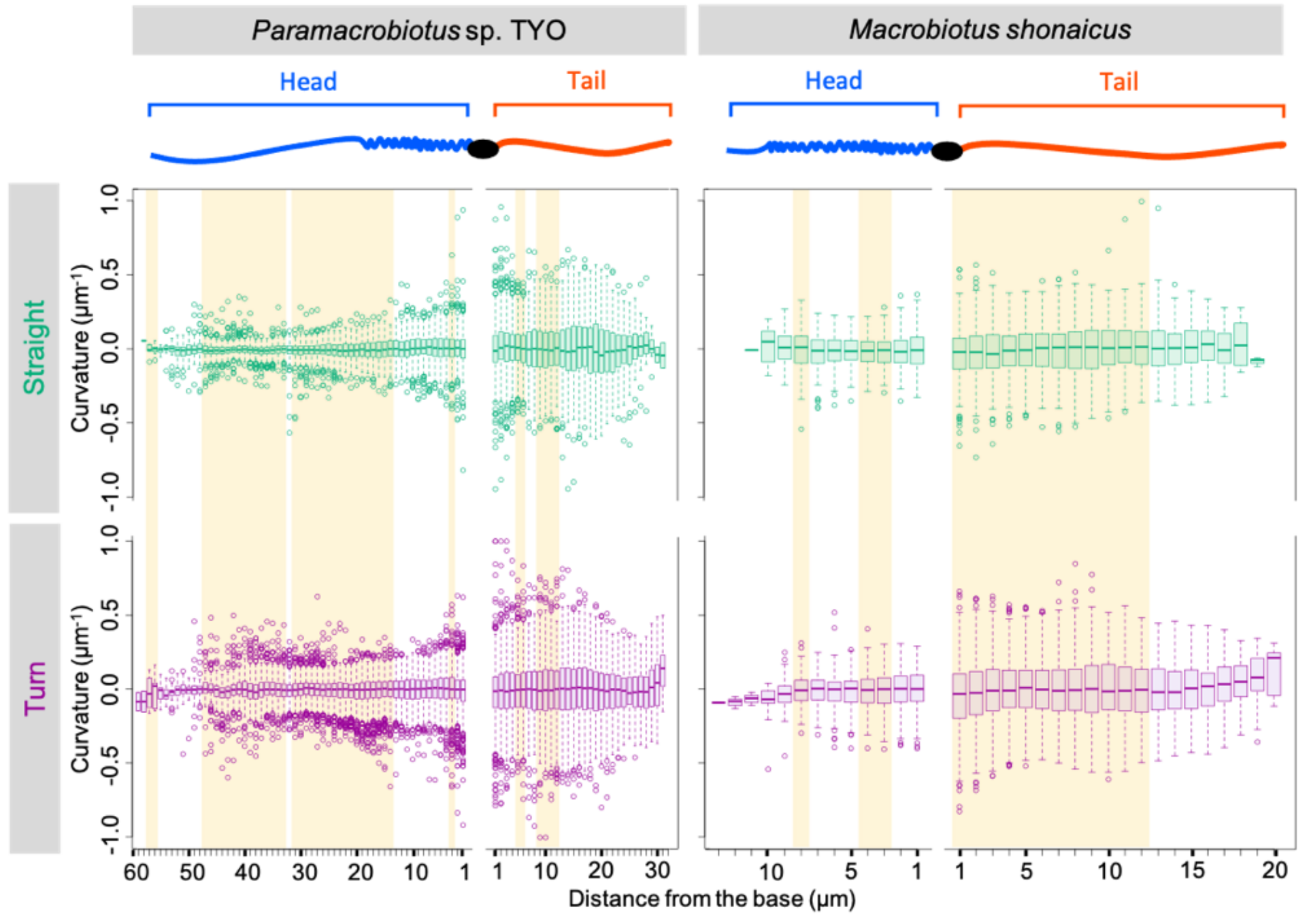

Figure 5

Spermatozoon movement comparison between swimming in a straight line and turning. Green and purple boxplots represent the curvatures of spermatozoa swimming in a straight line and turning, respectively. Yellow highlighted positions show significant differences in their movements (F-test, $p<0.01$ ). 


\section{Paramacrobiotus sp. TYO}
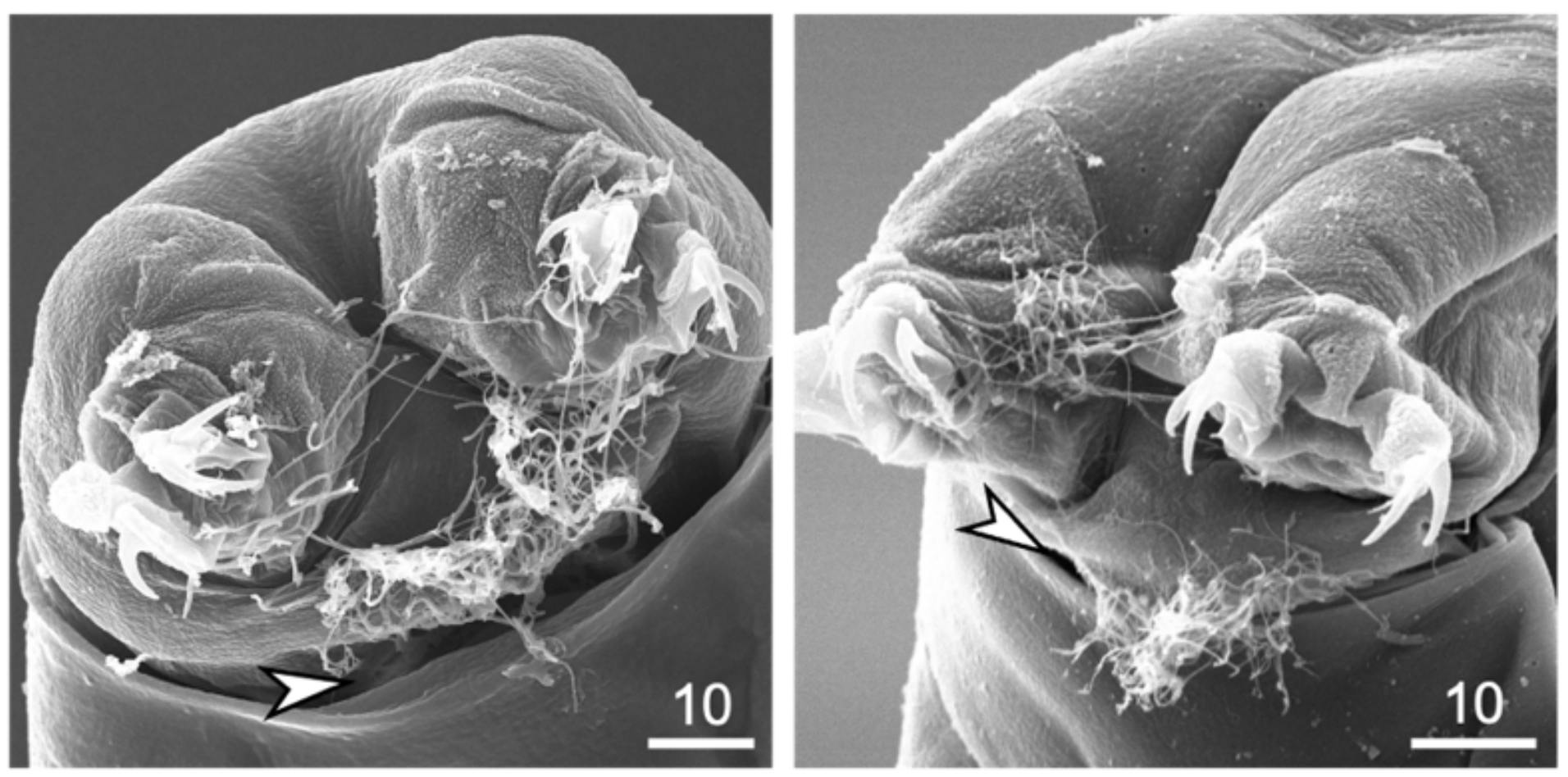

Figure 6

Spermatozoon aggregation. SEM photos of the cloaca of a mated female. The claws of legs IV are visible. Arrow heads indicate the cloaca. Scale bars: $\mu \mathrm{m}$.

\section{Supplementary Files}

This is a list of supplementary files associated with this preprint. Click to download.

- paramacrobiotus.mp4

- shonaicus.mp4

- supplespermwaves.gif 